\title{
A REFERENCIALIDADE DESLIZANTE: ENTRE OS EFEITOS DE REAL E DE SUJEITO
}

The sliding referentiality: between the subject-effect and the effect of reality

Andreia Tamanini*

\section{RESUMO}

A noção de significante desenvolvida por Jacques Lacan parece ter sido apropriada por Roland Barthes em seus ensaios posteriores à publicação dos Écrits daquele, em 1966. Pretendemos trazer a releitura que fizemos de O Rumor da Língua, de Barthes, supondo perceber aquela "entonação" de uma certa poiesis barthesiana, percebida por seus editores franceses. Nossa suspeita é de que o conhecido 'efeito de real' barthesiano - conceito muito importante para os estudos histográficos de um modo geral, e da teoria da história em particular, sobretudo ao lidar com a análise e interpretação de textos literários classificados como realistas e nos ditos "romances históricos"- tenha sido concebido por uma re-elaboração de R.B. da ideia lacaniana de efeito-sujeito.

Palavras chave: Efeito de real, efeito-sujeito, Barthes, Lacan, significante.

\footnotetext{
* Programa de Pós-Graduação em História Social /Universidade Federal do Rio de Janeiro (PPGHIS/ UFRJ). Rio de Janeiro, Brasil. Correo eletrónico: andreia.tamanini@gmail.com

Artículo recibido el 12 de julio de 2017. Aceptado el 19 de enero de 2018.
} 


\begin{abstract}
The sense of signifier as developed by Jacques Lacan seems to have been appropriated by Roland Barthes in his essays after the publication of Lacan's Écrits in 1966. We intend to bring out our refreshing-reading of Barthes's The Rustle of Language, supposing to achieve that 'intonation' of a certain Barthesean poiesis as it was perceived by its French publishers. We assume that the well-known Barthesian 'effect of reality' -a very important concept for historiographical studies in general, and for the theory of history in particular, especially when dealing with the analysis and interpretation of some literature classified as realist and the so-called 'historical romances'- has been conceived by RB's re-elaboration of the Lacanian idea of subject-effect.
\end{abstract}

Keywords: Effect of real, subject-effect, Barthes, Lacan, signifier.

O livro O rumor da língua ${ }^{1}$ reúne postumamente escritos curtos, transcrições de conferências, ensaios ou artigos avulsos de Roland Barthes. A seleção fora realizada por seus editores franceses, dentro da série Essais Critiques, da editora Seuil. Os textos são datados desde 1964 até 1980 e não seguem uma sucessão cronológica, em favor, segundo seus editores dos Essais, de um rearranjo tal que, em vez de simplesmente seguir a ordem na qual foram redigidos, permitisse a organização "dentro da temática e da entonação de um trabalho -de uma invenção- do qual se apercebe, à cada instante, que, quanto mais fosse ele, próprio, de R. B., mais ele nos concerne a todos" ${ }^{2}$. E nós não nos escusamos de incorporar essa premissa.

Como bem observa Leyla Perrone-Moisés, no prefácio da edição brasileira de 2004, pela Martins Fontes, a organização dos ensaios não parece (nem pretende) formar entre si um todo homogêneo, e a eventual relação entre cada parte do livro exigiria, talvez, obsequiosa complacência ou uma boa dose

\footnotetext{
${ }^{1}$ Barthes, 2004.

${ }^{2}$ Barthes, 1984, p. 6. As traduções ao português neste trabalho são da autora.
} 
de criatividade analítico-interpretativa. A proposta aqui é menos engajar-nos nesse despropósito do que compor um elo conceitual que tenha levado Barthes a conceber o 'efeito de real' (effet de réel). E, no desdobramento da releitura do texto, suspeitamos de um forte vínculo com o efeito-sujeito proposto por Jaques Lacan ([1966] 1999). A ideia de significante lacaniano parece ter sido apropriada por Barthes desde seus ensaios posteriores à publicação dos Écrits de Lacan, em 1966. Partiremos, para isso, em um volteio temporal, do ensaio O rumor da língua, de 1975, e chegar a O efeito de real, de 1968, supondo perceber aquela "entonação" de uma certa poiesis barthesiana, por assim dizer, apresentada nos dois ensaios. Nossa suspeita é de que o conhecido efeito de real -conceito importante para os estudos histográficos e da teoria da história em especial hoje, ao lidar com a análise e interpretação de textos de ficção, sobretudo na literatura que leva a etiqueta de realista e nos ditos "romances históricos"- tenha sido concebido por uma elaboração de R.B. do conceito lacaniano. E a pedra de toque, a liga que permitiria a moldagem desse elo entre ambos os 'efeitos', segundo procuraremos expor, estaria na torção sugerida por Lacan do conceito de significante, pondo-o como base modular para a estruturação da linguagem, pela qual se produz o que este chamou de "efeitosujeito", quando, do deslizamento contínuo de uma cadeia de significantes, o signo cede seu lugar ou se funde com estes, abrindo espaço, o vazio, que enseja o movimento dos significantes por meio da e na linguagem.

A releitura do livro adveio de uma dúvida acometida acerca do motivo pelo qual Barthes teria conferido esse título ao artigo que dá o nome ao livro: por que "rumor da língua"? A primeira resposta trouxe-a o próprio R. B:

O rumor é o barulho daquilo que está funcionando bem. Seguese o paradoxo: o rumor é um barulho limite, o barulho daquilo que, funcionando com perfeição, não tem barulho; rumorejar é fazer ouvir a própria evaporação do barulho: o tênue, o camuflado, o fremente, são recebidos como os sinais de uma anulação sonora ${ }^{3}$.

\footnotetext{
${ }^{3}$ Barthes, 2004, p. 94.
} 
Ouvir rumorejar a língua indicaria seu perfeito funcionamento. Seja em um aeroporto na China ou em um hall no Japão, o rumorejo da máquina significa o anular-lhe, ao movimento de sua engrenagem -ao exercício fonético da língua-, seu barulho. O significante, segundo a linguística clássica, é bom que lembremos, consiste na parcela material, por assim dizer, de um signo: basicamente o seu som e sua imagem gráfica ${ }^{4}$. O rumor poderia ser, em última instância, então, se o entendemos bem, o ressoar da própria evaporação da matéria por que se concretiza a língua - seu elemento significante. Poderia ser o deixar dissolver - ou tornar tênues, camufladas, frementes- as amarras que retêm uma forma qualquer, fixa, de identidade semântica ao que se fala, à motilidade das palavras com o que se processa - “com perfeição"-a linguagem. A coisa complica se tomamos, ainda, o discurso de sua aula inaugural do Collège de France 5 :

A linguagem é uma legislação, a língua é seu código. Não vemos o poder que reside na língua, porque esquecemos que toda língua é uma classificação, e que toda classificação é opressiva: ordo quer dizer, ao mesmo tempo, repartição e cominação. Jakobson mostrou que um idioma se define menos pelo que ele permite dizer, do que por aquilo que ele obriga a dizer. Em nossa língua francesa (e esses são exemplos grosseiros), vejo-me adstrito a colocar-me primeiramente como sujeito, antes de enunciar a ação que, desde então, será apenas meu atributo: o que faço não é mais do que a consequência e a consecução do que sou [...]. Assim, por sua própria estrutura, a língua implica uma relação fatal de alienação. Falar, e com maior razão discorrer, não é comunicar, como se repete com demasiada frequência, é sujeitar: toda língua é uma reição ${ }^{6}$ generalizada.

Se a língua é "fascista", normativa, se ela "sujeita" e "obriga a dizer", como destituí-la de sua fixidez nomológica, sua condição de "reição [sic] generalizada", e transformá-la em murmúrio tênue, frente ao transcurso dos

\footnotetext{
${ }^{4}$ Saussure, 2002, pp. 79-81.

${ }^{5}$ Barthes, 2007, pp. 11-12.

${ }^{6}$ Atente-se que não foi encontrada qualquer entrada do termo reição em nenhuma das publicações de referência lexicais ou de estudos em linguística por nós consultadas. O excerto, no original francês, é: “ [...]
} 
sentidos que se opera? Ou seja, de que forma ela se dissolve em favor dela mesma ou da linguagem? A partir de que mecanismos um sistema opressor, ao bem funcionar, alcança tal grau de suavidade, de imaterialidade, de fluidez? Ao que, então, está referindo-se o semiólogo francês quando alvitra essa "evaporação"? O que outorga à língua essa liberação de seu compromisso com sua materialidade sonora incondicional, com sua inteligibilidade, sem que, com isso, ela perca -ou, pelo contrário, reafirme- sua função como meio de linguagem?

O que parece ser uma aporia, apresenta-se-nos como a chave para abrirlhe uma saída e desvendar seu próprio enigma. Pois, em outro passo do ensaio precedente, Digressões, datado de 1971, nessa mesma seção do Rumor da língua, nosso autor discorre sobre uma ideia que, segundo defendemos, está na base desse processo de "evaporação". Trata-se do conceito de 'significante', crucial para a linguística. Mas, assim entendemos, Barthes o emprega -e esse é o deslocamento necessário para a concepção do rumor- no sentido reformulado por Lacan ${ }^{7}$. E podemos perceber isso de maneira mais ou menos clara (ainda que muito breve) quando nosso autor convoca a todos que retirem do significante a carga que lhe dá a tradição saussuriana e a tomem como uma "palavra-numen", ao qual atrela o aposto "palavra capaz de armar um discurso".

Parler, et à plus forte raison discourir, ce n'est pas communiquer, comme on le répète trop souvent, c'est assujettir: toute la langue est une rection généralisée“ (Barthes, [1977] 2002, p. 12). De acordo com o dicionário francês Le Petit Robert, a definição da palavra rection é: "Propriété qu'a le verbe d'être accompagné d'un complément direct ou introduit par une préposition“. Deste modo, cremos que a melhor forma de traduzir o referido vocábulo fosse talvez recorrer ao termo português regência. Foi, aliás, desta forma que Ana Mafalda Leite traduziu-o na edição portuguesa da obra em apreço (Barthes, 1988). Optamos, pois, por manter-nos fieis à tradução brasileira, de Mario Laranjeira, publicada pela Cultrix, mas com esta ressalva.

${ }^{7}$ Importante, cremos, atentar para a relação que Lacan estabelece com a teoria linguística na formulação de sua noção de sujeito, advinda esta da de significante. Para tal, recomendamos a leitura de Arrivé, Michel. "Saussurian Signifier and Lacanian Signifier". In Linguistics and Psychoanalysis: Freud, Saussure, Hjelmslev, Lacan and Others. With a preface by Jean-Claude Coquet. Translated from the French [1986] by James Leader. Philadelphia: John Benjamins, 1992, pp. 121-142.

${ }^{8}$ Note-se que numen, no seu emprego latino clássico significava o aspecto de natureza divinizante, sua manifestação como a potência divina dos entes, fossem esses dii ou diui. 
Segundo ele, o significante seria um termo contraditório, ao mesmo tempo algo nietzschianamente leve, e onde, no entanto, deve-se "imergir nele, mergulhar longe do significado, na matéria, no texto".

O significante, como dissemos, segundo a definição formulada por Ferdinand de Saussure ${ }^{10}$, é a imagem acústica ou visual, ou seja o elemento formal, a "face externa", do signo - do qual a interna é o significado. Para Saussure, o significante consente, no plano da língua, identificar as diversas realizações fônicas concretas que se colocam sobre o plano da palavra. E o significado confere valor semântico que designa um conceito atrelado ao significante. Ambos, significante e significado, formam um par indissociável, e, somados, constituem o signo, que é a unidade básica da transmissão linguística, como representação de um dado referente ao qual remete. Saussure advoga ainda que é do signo - e não do significante- que podem ser extraídos, seja por conexão ontológica ou simplesmente analógica, indícios, deduções ou conhecimento sobre esse referente - ou seja, em última instância, é o signo o representante do real no mundo da linguagem. Para este autor, por conseguinte, o significante tem função apenas de suporte para o significado e para a compleição formal do signo.

Lacan, por sua vez, não chegou a definir o seu signifiant ${ }^{11}$, mas dele escreve que "um significante representa um sujeito para outro significante"12. Ora, que a definição falte talvez não seja uma casualidade. De fato, o conceito lacaniano parece não pretender ser descritivo mas, como objeta Benvenuto ${ }^{13}$, “adscritivo"14 (atributivo). Em outras palavras, ele não 'descreve' uma qualidade do sujeito - 'qualifica-o', atribui-lhe algum predicado ou alguma coisa. Pode ser, portanto, anulado a qualquer instante. O significado de um significante -

\footnotetext{
${ }^{9}$ Barthes, 2004, pp. 90-91.

${ }^{10}$ Saussure, 2002, pp. 79-81.

${ }^{11}$ Vicenzi, 2009.

${ }^{12}$ Lacan, 1999, p. 840.

${ }^{13}$ Benvenuto, 2013.

${ }^{14}$ Adscrito, segundo o dicionário Houaiss, envolve, dentre outras acepções, um atributo que é acrescentado a algo ou alguém, arrolando-lhe um papel ou inscrevendo-o em um determinado serviço.
} 
como toda coisa adscrita- não vem fixado em uma via definitiva, porque não carrega um número preciso de condições suficientes e necessárias para defini-lo. A fidelidade a Saussure é, pois, posta drasticamente em questão, já que, enquanto este valorizaria sobretudo a relação significante-significado (signifié), o algoritmo lacaniano acentuaria, em câmbio, a barreira, a resistência que defasa o significante em sua conexão com o significado ${ }^{15}$. O significante se apresentaria sempre no seu deslizar. Interessante, aliás, que Lacan, integrando Freud a Saussure, utilize não o substantivo "significação" (signification), presente na obra deste, mas o advérbio "significável" (signifiable), para exprimir algo análogo, se bem que menos estável: "o significante tem função ativa na determinação dos efeitos nos quais o significável aparece enquanto o substitui como marca, tornando-se através dessa paixão o significado" ${ }^{16}$. Ou ainda "[o falo] pode desenvolver o seu papel somente enquanto velado, isto é, como o mesmo signo de latência da qual é tomado todo significável, tão logo este venha a ser suspenso (aufgehoben) pela função significante" ${ }^{17}$. É de se notar que o signo perde o protagonismo da fatoração semântica, transferido este para o significante, que atende não mais às adjudicações do significado, mas aos efeitos que provoque nos engendramentos atributivos -impermanentes- dos sujeitos da interlocução.

O confronto com Saussure complica-se quando Lacan apresenta sua definição de signo, como sendo "aquilo que representa alguma coisa para alguém", distinto do signo concebido por Saussure, para quem o signo é resultado da soma de um significado com um significante $(\text { signifié })^{18}$. Pela perspectiva lacaniana, por sua vez, pode-se afirmar que o significante é sempre, também, um signo -de um sujeito. Eis o fundamento para o efeito-sujeito- que fornece,

\footnotetext{
${ }^{15} \mathrm{Cf}$. o verbete Le signifiant no Dictionnaire do sítio eletrônico da Association Lacanienne Internationale. Também Lacan, 1999, pp. 500-515.

${ }^{16}$ Lacan, 1999, p. 688.

${ }^{17}$ Lacan, 1999. p. 703.

${ }^{18}$ Cf. e.g. Radzinski, 1985, pp. 117-124 e Arrivé, 1992, pp. 121-142.
} 
segundo nosso argumento, ensejo às reflexões de Barthes no Rumor da língua e para a formulação de seu conceito de efeito de real. O significante é, portanto, representativo, só que representa (é signo de) não objetos, mas (de) sujeitos.

E o que significa esse sujeito, produzido como efeito por mobilização de um e outro significante?

Consideremos, pois, o que Lacan quer dizer ao elencar a palavra sujeito para integrar seu discurso. Se pensamos no sujeito cartesiano, por exemplo, podemos inferir que este não pode duvidar de si, do contrário não existiria; ele é porque pensa, e, então, existe (cogito ergo sum ${ }^{19}$ ). No entanto, a esse sujeito cognitivo (ego cogitans) é concedido duvidar de tudo o mais, ou seja, da existência de tudo quanto seja outro. Nada tem seu lugar garantido na sua relação com a verdade logo, com o real exterior ao cogito/ego - se não puder sustentar-se diante desse sujeito que duvida. E o sujeito se afirma, portanto, por esse duvidar constante ${ }^{20}$. Já o sujeito para a linguística é definido como "o elemento de uma sentença que sofre a predicação" ${ }^{21}$. Em outras palavras, o sujeito é aquilo ao qual atribuímos ou negamos determinadas características. Ambas as elaborações de sujeito apontam para uma ausência, um vazio subjacente que permite seu preenchimento por uma função que os completa em termos de produção de sentido - o próprio sujeito.

O conceito de sujeito lacaniano foge, por um lado, da concepção cartesiana, que liga o sujeito a um eu irredutível, que existe enquanto $\operatorname{cogito}^{22}$, ao mesmo tempo, que da ideia saussuriana de signo e significante. Como vimos, foi deste último que Lacan concebeu a reversão pela qual o significante toma o lugar do signo como produtor do fenômeno da subjetivação. E a predicação do sujeito, assim com ele próprio se faz em uma cadeia por onde os significados escorrem, fluidos, evanescentes.

\footnotetext{
${ }^{19} \mathrm{Cf}$. Descartes, Princípios de filosofia (Principia philosophiae), 1, 7 e 10, 1644.

${ }^{20} \mathrm{Cf}$. a dúvida hiperbólica e a hipótese do Malin Génie, na primeira das Meditações metafísicas.

${ }^{21}$ Kristeva, 1971, pp. 107-126.

${ }^{22}$ Cf. o verbete Le sujet do Dictionnaire no sítio eletrônico da Association Lacanienne Internationale.
} 
Lacan extraiu a ideia de sua experiência psicanalítica, em que os relatos de seus pacientes apresentavam variantes que punham em xeque a fórmula de Saussure $^{23}$. Anoção de signo deveria ser relativizada, advertiu, então, o psicanalista, já que uma relação mais ou menos fixa entre significante e significado estaria restrita a um dado contexto subjetivo. Por outro lado, na linguagem como um todo, isto é, no lugar do Outro, só existiriam significantes. Aliás, Lacan define o Outro precisamente como “tesouro dos significantes". O sujeito, por sua vez, nunca está a priori, apenas como preenchimento provisório de um vazio, como ausência latente. O sujeito, portanto, não possui uma substância. Sua caracterização ou significado estaria na dependência da predicação. Essa, por sua vez, é constituída de significantes, os quais, do ponto de vista lacaniano, são os próprios artífices do significado a partir das relações que estabelecem com outros significantes na cadeia linguística.

Tenhamos em mente, portanto, que, do ponto de vista lacaniano, é por sobre o Outro, que desliza a cadeia significante que nos pode determinar. É lá que se encontram a trafegar os significantes que nos representam para outros significantes $^{24}$. Dito de outro modo, o que Lacan pretende expressar com sua fórmula parece ser a tese de que tudo o que decorre do 'eu' estaria na dependência da atribuição significante do Outro. Não terá sido por acaso que nessa primeira etapa de sua obra Lacan definiu o inconsciente justamente como o "discurso do Outro". De fato, eis o que diz o psicanalista francês sobre o tema: "O Outro é o lugar em que se situa a cadeia do significante que comanda tudo que vai poder presentificar-se do sujeito, é o campo desse vivo onde o sujeito tem que aparecer" ${ }^{25}$. É no campo do Outro que de modo autônomo os significantes se articulam uns aos outros produzindo a subjetividade como um mero efeito ${ }^{26}$.

O sujeito estaria, por assim dizer, como em um limbo. Ele parece

\footnotetext{
${ }^{23}$ Ogilvie, 1987, pp. 62-78.

${ }^{24}$ Amirault; Cottet; Quénardel; Roch; Pernot. s/d.

${ }^{25}$ Cf. Lacan, 1985, pp. 193-194.

${ }^{26}$ Cf. e.g. Ogilvie, 1987.
} 
imediatamente impedido ao jogo dos significantes e, no entanto, não pode advir como sujeito senão na medida em que o jogo dos significantes o fazem significável, interditando-o ou subtraindo-o para o movimento mesmo que o traz ao mundo. Contudo, em a relação se estabelecendo entre o sujeito não mencionável e a especificidade dos significantes que se organizam em seu lugar, a ordem dentro da cadeia de significantes torna-se essencial: se um "significante unário" representa de início o sujeito, o significante binário terá de anular esse mesmo sujeito, do qual ele revelará a inconsistência. De fato, como o sujeito conseguiria se pensar como uma unidade por meio dos outros? O sujeito aparece sempre a si mesmo como uma "exceção", como um "menos-um". Dito de outra forma, a função acordada ao sujeito como a "um", não seria jamais aquela da unidade unificante (Einheit), mas aquela da unidade distintiva (Einzigheit), que Lacan chama de "traço unário".

Assim, inicialmente lugar vazio, o sujeito vai adquirindo substância -uma substância sempre provisória, diga-se- ao ser preenchido com as significações vindas do campo do Outro, constituindo-o como mero efeito da circulação na cadeia de significantes.

E parece-nos ser precisamente nesse sentido que Barthes concebe a sua “evaporação do barulho", o "rumorejar" da língua. Uma cadeia de significantes que se descola de seus significados, exercendo apenas sua materialidade fônica, seu murmúrio, repassado a diversos Outros, já sem objetivação precisa, que somam-se continuamente na constituição efêmeros efeitos- sonoros, de sentidos, de subjetividades. E será na extensão da ideia sobre a figuração do sujeito lacaniana, repassada ao real, por meio da literatura - esta é nossa proposta- que Barthes construirá seu conceito de efeito de real. Senão vejamos.

O curto ensaio fora publicado originalmente em 1968, na revista Communications (vol. 11) e consiste em uma revisão crítica de Introdução à 
análise estrutural dos relatos ${ }^{27}$, publicado na mesma revista em 1966 (vol. 8), no qual ele próprio propunha a análise do relato fundamentada na linguística estruturalista. Em O efeito de real (L'effet de réel) Barthes expõe, então, uma abordagem que se distancia daquela de seu ensaio anterior, no qual chamava de "enchimentos" e "uxos" as descrições da narração ficcional ou histórica, à maneira de como haviam sido denominados pela crítica estruturalista, ou seja, como "aparentemente inúteis" crítico a si mesmo, essas descrições são recolocadas como parte fundamental de um discurso particular "realista". Essa crítica que Barthes faz à sua própria incursão no estruturalismo linguístico parece-nos um sugestivo indício da leitura que o autor possa ter feito de Lacan e seu efeito-sujeito. Note-se que Lacan publicou seus escritos justo em 1966.

No início do texto, Barthes traz exemplos de descrições em obras de Flaubert (Um coração simples, de 1877) e de Michelet (Relato sobre a morte de Charlotte Corday, de 1855). Em uma análise estrutural (como a de 1966, que motivou a crítica), tais observações são omitidas como detalhes supérfluos em relação à estrutura ou vêm denominados como "catálise" ou "enchimento", com um valor funcional indireto, somente recuperáveis na estrutura como indícios de caráter ou de atmosfera. Segundo indica o autor, as descrições parecem não ter nenhuma finalidade que justifique a referência aos objetos em questão (no caso de Flaubert, o barômetro acima do piano e, no de Michelet, uma precisão sobre o tempo transcorrido para a chegada do pintor à prisão de Charlotte Corday), mas por que então seriam tão incidentes na literatura ocidental realista?

Em primeiro lugar, Barthes assinala o caráter analógico da descrição em contraste com a estrutura preditiva do relato, conforme se apregoa ao enredo

\footnotetext{
${ }^{27}$ Barthes, 1966, pp. 1-27.

${ }^{28}$ Barthes, 1966, p. 6.
} 
do herói (se age de tal maneira, se escolhe tal alternativa, chega a tal fim): "sua estrutura é puramente aditiva e não contém essa trajetória de opções e alternativas que dá à narração o desenho de um vasto dispaching" ${ }^{\text {"29 }}$, pelo qual se conforma como parte das linguagens "superiores". Barthes conclama aí a uma reversão da análise estruturalista para encontrar a significação da descrição "insignificante". E aqui o semiólogo procede com sua primeira torção - tal qual fizera Lacan- das prerrogativas saussurianas: são aqueles detalhes supérfluos, puramente materiais e desnecessários que conferem à narrativa sua potencialidade de representar o real. A obra de Flaubert estaria regida pelo "verossímil estético", afirma Barthes, cujo sentido é auferido pela sua resposta a regras culturais da representação e a "imperativos realistas"30.

De fato, na estrutura da narrativa flaubertiana como na de Michelet, o artifício da descrição tem papel preponderante. Já nos relatos estudados por Barthes no ensaio de 1966, a descrição tinha sempre finalidade ornamental, apresentando, inventando ou esboçando uma pessoa, evento, lugar ou sentimento, para que o leitor os pudesse imaginar de forma mais visual e concreta, cumprindo função muitas vezes complementar, não se encontrando necessariamente submetida ou vinculada à verossimilhança referencial da história reportada. Eis o eixo em torno do qual pivota a transferência, ao componente antes secundário da representação narrativa, da função principal da transmissão estético-enunciativa sugerida por Barthes. Dito de outro modo: a narrativa avança em sua proximidade analógica com o real à medida que essa transferência é bem sucedida na produção de um efeito de realidade (ou, mais precisamente, "efeito de real"), ou seja, quando o detalhe "insignificante", desnecessário, passa a atuar como um lugar vazio de sentido, aberto ao signifiant lacaniano, que, sempre atribuído pelo Outro $-\mathrm{o}$

\footnotetext{
${ }^{29}$ Barthes, 2004, p. 183.

${ }^{30}$ Barthes, 2004, p. 185.
} 
leitor-, ganha estatuto de um efeito em uma cadeia de (in)significantes - os objetos descritos. Caiba ressaltar, talvez, que o movimento da torção de Barthes a produzir esse efeito de real alcança esse status de significante por uma operação apenas aparentemente inversa a do efeito-sujeito proposto por Lacan: de fato, não é uma falta ou lacuna (de significantes) anterior que o instaura, senão justamente de um 'excesso' (de objetos) - mas um excesso de objetos aos quais falta um significado diretamente apreensíveis como referência (imputável - ou significável) de real. Diferente do sujeito, é o supérfluo, o aparentemente vazio de sentido, que abre espaço para o real ver-se representado na situação de efeito. Isso tendo-se em conta, talvez valha a pena lembrar, que o real, como tal, segundo Lacan, restaria sempre impenetrável à simbolização do sujeito ${ }^{31}$.

O "imperativo realista" a que se refere Barthes supõe uma adscrita (e, portanto, atribuída poralguém e não inerenteà coisa) "exatidão referente"-ilusória, adverte ele- que, por sua vez, justificaria a descrição, uma vez que remeteria àquilo que "aconteceu realmente", a "realidade concreta", tal qual ocorreria com o relato histórico. De maneira que a narrativa realista se aproximaria da histórica na medida em que se apropria desses "pormenores supérfluos", que confeririam à história sua autoridade objetiva. $\mathrm{O}$ assim chamado realismo, portanto, não se

\footnotetext{
${ }^{31}$ O real tem um estatuto peculiar em Lacan, pelo fato de ser considerado inalcançável: "L'acte (sexuel) est impossible. Quand je dis ça, je ne dis pas qu'il n'existe pas, ça ne suffit pas qu'on le dise, puisque l'impossible c'est le Réel, tout simplement, le Réel pur, la définition du possible exigeant toujours une première symbolisation: si vous excluez cette symbolisation, elle vous apparaîtra beaucoup plus naturelle, cette formule de l'impossible, c'est le Réel. Il est un fait qu'on n'a pas prouvé, de l'acte sexuel, la possibilité dans aucun système formel“ (cf. Lacan, Séminaire XIV, La logique du fantasme, sessão de 10 mai 1967). Tal declaração remete à noção de impossível conforme solicitada por Lacan, ou seja, o impossível está já lá, escapa ou resiste à simbolização. Para tal, cf. Lacan, Jacques. Le séminaire, Livre XI, Les quatre concepts fondamentaux de la psychanalyse. Paris: Seuil, 1973, p.152. Ali o psicanalista discorre sobre o possível como secundando em relação ao "real puro", ou ao "existente", e não prévio a ele. Isso equivaleria a dizer que o impossível não é a negação do possível. No Séminaire $I X$, L'identification, em que cita Kant sobre o real: Ein leerer Gegenstand ohne Begriff (Um objeto vazio impossível de ser capturado pelo conceito). Ou em Lacan, Jacques. Le Séminaire. Livre IV. La relation d'objet. Paris: Seuil, 1994, p. 429: "C'est parce que l'on part d'une formalisation symbolique pure que l'expérience peut se réaliser correctement, et que commence l'instauration d'une physique mathématique... On n'y est pas parvenu avant de faire cette séparation du symbolique et du réel“".
} 
inseriria nos moldes da retórica clássica conforme demonstrada no texto, mas requereria suas próprias finalidades e justificativas, que, na notação realista, responde a uma exigência dupla: em primeiro lugar, a função estética que dá o sentido de "peça" à descrição, ao mesmo tempo em que a limita em extensão. Em segundo, esta limitação mesma compete para atestar, pela seleção do referente a ser deduzida como realidade, a objetividade do seu discurso ${ }^{32}$.

A representação do concreto e do vivido apareceria como uma resistência ao sentido "como por uma exclusão de direito, o que está vivo não pudesse significar"33. E mais: aparece como dissolução.

O significante a que Barthes se refere ao longo do texto não é o da linguística, mas um outro, mais próximo à proposição lacaniana. Dissemos, no entanto, que o efeito de real constitui-se a partir de um excesso, em vez da falta concernente a toda função sujeito e primordial para a noção, tanto de significante e efeito-sujeito de Lacan, quanto para a de rumor da língua de Barthes. Como, então, associam-se esses conceitos? Não será outro senão o próprio semiólogo francês a nos socorrer do apuro.

Antes, porém, lembremos que todo sujeito pressupõe uma ausência, uma lacuna que ensejará sempre preenchimento por um termo ao qual atribui-se uma predicação. Também que o sujeito lacaniano surge como uma representação de significante para significante; o significante, porém, não cessa de apagar o rastro do sujeito à medida que desenrola sua cadeia. Mas onde afinal o efeito de real encontra-se com o efeito-sujeito e o rumor da língua? E eis o que Barthes nos responde, quando discorre sobre a "ilusão referencial", em $O$ efeito de real:

A verdade dessa ilusão é a seguinte: suprimido da enunciação realista a título de significado de denotação, o real volta a ela a título de significado de conotação; no momento mesmo em que se julga denotarem tais

\footnotetext{
${ }^{32}$ A crítica de Rancière (2010) a Barthes, caiba comentar, diz respeito propriamente a este auto-referente que circunscreveria o real a um mero objeto residual do discurso. Comentaremos sobre ele mais adiante. ${ }^{33}$ Barthes, 2004, p. 189.
} 
detalhes diretamente do real, nada mais fazem sem o dizer, do que significá-lo; o barômetro de Flaubert e a pequena porta de Michelet afinal não dizem mais do que: somos o real; é a categoria do real (e não seus conteúdos contingentes) que é então significada; noutras palavras, a própria carência do significado em proveito só do referente torna-se o significante mesmo do realismo; produz-se um efeito de real, fundamento dessa verossimilhança inconfessa que forma a estética de todas as obras correntes da modernidade.

Essa nova verossimilhança é muito diferente da antiga, pois não é nem o respeito das "leis do gênero" nem sequer a sua máscara, mas procede da intenção de alterar a natureza tripartida do signo para fazer da notação o simples encontro de um objeto e de sua expressão. A desintegração do signo - que parece ser a grande causa da modernidade- está certamente presente no empreendimento realista, mas de maneira algo regressiva, pois que se faz em nome de uma plenitude referencial, quando se trata, ao contrário, hoje, de esvaziar o signo e afastar infinitamente o seu objeto até colocar em causa, de maneira radical, a estética secular da "representação" 34 .

Ora, se de um lado o excesso funda o elemento deflagrador do efeito do real, que permite esse vácuo de significação denotativa, conformado na "verossimilhança inconfessa" embutida na "ilusão referencial", de outro, é a carência de significado que articula a cabotagem capaz de transferir o primado do referente imediatamente ao significante. Um excesso que cobre uma falta. Nosso autor opera aqui, parece-nos, uma delicada analogia entre o efeito de real e o efeito-sujeito lacaniano. E de então virá a desintegração do signo, sobre a qual comenta Barthes a seguir, que concederá ao referente -já feito significante- o atravessamento radical da barreira de qualquer significação até... o rumorejar do real. A referencialidade desse real se dissolve e se integra ao seu status significante dentro da descrição realista, ressaltando-a e, mais, validando-a.

Há de se observar, antes de concluirmos, a crítica feita por Jacques Rancière $^{35}$ acerca da auto-referencialidade textual do real barthesiano. Para

\footnotetext{
${ }^{34}$ Barthes, 2004, pp. 189-190.

${ }^{35}$ Rancière, 2010.
} 
Rancière, Barthes encerra sua análise a uma lógica estruturalista, redutora, cujo referente permaneceria interno ao texto, regido pelo estatuto da representação, resumido a um mero resíduo instrumentalizado para o campo linguístico. $\mathrm{O}$ demérito dessa maneira de circunscrever o real como efeito de uma referencialidade causal discursiva estaria no apagamento de sua componente política. Este parece ser um ponto importante frente aos desafios impostos às pesquisas no campo da historiografia, quando se deparam com o texto literário de uma maneira geral, pois traz a relevo a questão da referencialidade. Rancière objeta que essa captura à grade estruturalista restringiria a referencialidade dos objetos descritos e do próprio realismo literário a um estado de efeito de uma causa a priori que os justifique, retirando da ficção sua potência política ativa -e democrática- de um mundo exterior a ela - potência essa que se estabelece na vida, como abertura de alternativas. Até certo ponto, parece legítima a queixa. Entretanto, ratificando o que acabamos de propor, cremos ser necessário um certo deslocamento à proposição de Rancière. O real, em Barthes, embora tributando sua existência à linguagem, como procuramos expor, não está dado pela indução mediada pelo signo saussuriano, mas aparece como atribuição efêmera, múltipla e em contínuo fluxo -fazível pelo leitor-, como predicado, tal qual o efeito-sujeito dado pelo deslizamento significante lacaniano. Efetuase um processo de subjetivação do referente, não de objetivação. E o leitor está como um elo fundamental da cadeia, quem identifica e refaz o excesso de detalhes apresentado pelo texto do romance realista analisado por Barthes em lacunas de significado, e as ajuda a preencher, subjetivamente, operação esta necessária à realização do efeito de real. O papel do leitor como ator preponderante do jogo da linguagem propiciado pela leitura de um texto é conclamado por Barthes em diversas passagens dos artigos de O rumor da língua, como, por exemplo, neste trecho de Da obra ao texto:

O Texto é plural. Isso não significa apenas que tem vários sentidos, mas que realiza o próprio plural do sentido: um plural irredutivel (e não 
apenas aceitável). O Texto não é coexistência de sentidos, mas passagem, travessia; não pode, pois depender de uma interpretação, ainda que liberal, mas de uma explosão, de uma disseminação. O plural do Texto deve-se, efetivamente, não à ambiguidade de seus conteúdos, mas ao que se poderia chamar de pluralidade estereográfica dos significantes que o tecem (etimologicamente o texto é um tecido): o leitor do Texto poderia ser comparado a um sujeito desocupado (que tivesse distendido em si todo o imaginário); esse sujeito bastante vazio passeia (foi o que aconteceu ao autor destas linhas, e foi aí que ele captou uma ideia viva do Texto) no flanco de um vale em cujo fundo corre um oued (o oued foi colocado aí para atestar um certo estranhamento); o que ele capta é múltiplo, irredutível, proveniente de substâncias e de planos heterogêneos, destacados : luzes, cores, vegetação, calor, ar, explosões tênues de ruídos, gritos agudos de pássaros, vozes de crianças do outro lado do vale, passagens, gestos, trajes de habitantes aqui perto ou lá longe; todos esses incidentes são parcialmente identificáveis; provém de códigos conhecidos, mas a sua combinatória é única, fundamenta o passeio em diferença que nunca pode repetir-se senão como diferença [negrito nosso] ${ }^{36}$.

Portanto, se há, segundo acusa-o Rancière, um eixo pendular que opõe real e imaginário na fórmula barthesiana, eixo ao qual estejam subsumidos elementos funcionais do texto realista, o mecanismo que articula tais elementos operacionaliza-se compreendendo o sujeito-leitor - vivo e, por que não, político, que realoca a referencialidade do texto para o seu repertório de imaginário. Para Rancière, Barthes não consegue sair da lógica da representação. Com efeito, não defendemos que o faça. Contudo, não nos parece tratar de um mero "arranjo funcional de causas e efeitos que subordina as partes ao todo"; mais bem um vácuo propulsor da cadeia deslizante de significantes, em vez de um efeito que denuncie uma causa. Salientamos, por fim, que não pretendemos nem escudar a posição do semiólogo nem desmerecer a do filósofo, apenas chamar a atenção para que esse "efeito", atrelado a uma causa que o preceda, a que se refere Rancière quando refuta o real de Barthes, não é o mesmo sobre o qual estamos construindo nossa argumentação até aqui.

\footnotetext{
${ }^{36}$ Barthes, 2004, p. 70.
} 
Pensamos ter sido possível nesta breve reflexão apresentar o alinhavo de conceitos que venha a cerzir "O rumor da língua" e "O efeito de real", com base na interseção da teoria lacaniana do significante e o efeito-sujeito. Entendemos essa apropriação de Lacan como fundamento essencial do pensamento de Barthes na elaboração do conceito de efeito de real e esperamos que apontá-la aqui possa ser um contributo ao aprofundamento nas discussões sobre o tema e acerca dos meandros da própria teoria barthesiana, tão cara aos estudos contemporâneos em teoria da história, em especial no que tange a relação história e ficção. Cabe fazer notar que a percepção da interferência de Lacan sobre a obra de Barthes não é inédita entre os estudiosos desta ${ }^{37}$. Mas acreditamos termos podido somar positivamente nesse sentido, justamente ao colocar em relevo o impacto do conceito de efeito-sujeito e de significante lacanianos na concepção do efeito de real em Barthes. Parece-nos evidente que a dissolução do signo proposto no último parágrafo de "O efeito de real" colmate o nosso argumento, desde que aceitemos que há intercambiamento -nos moldes em que operou Lacan em sua cadeia de significantes- entre o referente e o significante ali, conforme elucidanos o próprio autor. O real se deixaria, então, intangível (como, aliás, figura o real para Lacan) e apenas verificável como efeito: instável, evanescente tal qual o sujeito lacaniano, em uma cadeia de significantes-referentes. Poder-seia depreender daí, talvez, que o real só possa existir enquanto significante que represente para outro significante. E, no extremo, o algo do qual possamos saber apenas o murmúrio - o rumor que atesta o seu bem funcionar.

\footnotetext{
${ }^{37}$ Por exemplo, podemos citar Roland Champagne (1984), que assinala a importância das ideias de desejo e inconsciente lacanianas em Barthes, ou Margaret Iversen (2007), no que concerne ao evidente interesse do semiólogo francês pela discussão de Lacan sobre o olhar.
} 


\section{Referências}

Amirault, Monique; Cottet, Serge; Quénardel, Claude; Roch, Marie-Hélène; Pernot, Pascal. Du sujet de l'inconscient au parlêtre. In Association de Psychanalyse. École de la cause Freudienne. Sítio eletrônico. Disponível em:http://www.causefreudienne.net/du-sujet-de-linconscient-au-parletre/.

Arrivé, Michel. Saussurian Signifier and Lacanian Signifier. In Linguistics and Psychoanalysis: Freud, Saussure, Hjelmslev, Lacan and Others.

Translated from the French [1986] by James Leader. Philadelphia: John Benjamins, 1992: 121-142.

Barthes, Roland. O efeito de real. In O rumor da língua. Trad. Mário Laranjeira. São Paulo: Martins Fontes, 2004: 181-190. - Digressões. In O rumor da língua. Trad. Mário Laranjeira. São Paulo: Martins Fontes, 2004: 81-92. - O rumor da língua. In O rumor da língua. Trad. Mário Laranjeira.

São Paulo: Martins Fontes, 2004: 93-97. -. Da obra ao texto. In O rumor da língua. Trad. Mário Laranjeira. São Paulo: Martins Fontes, 2004: 65-75. Le bruissement de la langue - Essais Critiques IV [no original francês]. Paris: Ed. du Seuil, 1984.

------. Aula. Pronunciada em 7 de janeiro de 1977. Trad. Leyla PerroneMoisés. São Paulo: Cultrix, 2007. - Lição. Lisboa: Edições 70, 1988.

Leçon. Texte de la leçon inaugurale prononcée le 7 janvier 1977 au Collège de France. Paris: Seuil, 2002. .."Introduction à l'analyse structurale des récits". Communications

- Recherches sémiologiques: l'analyse structurale du récit. 8 (1966): 1-27. Disponível em: www.persee.fr/doc/comm_0588-8018_1966_ num_8_1_1113.

Benvenuto, Sergio. "Il significante - tra Saussure e Lacan”. European Journal of Psychoanalysis (18 luglio 2013). Disponível em: http://www.journalpsychoanalysis.eu/il-significante-tra- saussure-e-lacan/.

Champagne, Roland A. Literary History in the Wake of Roland Barthes: ReDefining the Myths of Reading. Birmigham: Summa Pubns, 1984.

Descartes, René. Princípios de filosofia (Principia philosophiae). Lisboa: Edições 70, [1644] 1997. 
Iversen, Margaret. "What is a Photograph?". In Beyond Pleasure: Freud, Lacan, Barthes. Pennsylvania: Penn State University Press, 2007.

Kristeva, Julia. "Du sujet en linguistique“. Langages - Épistémologie de la linguistique [Hommage à E. Benveniste] 6 (24) (1971) : 107-126. Disponível em: http://www.persee.fr/docAsPDF/lgge_0458726x_1971_num_6_24_2609.pdf.

Lacan, Jacques. Écrits. Paris: Ed. du Seuil, [1966] 1999. O Seminário. Livro 11. Os quatro conceitos fundamentais da Psicanálise. Coleção Campo Freudiano no Brasil. Rio de Janeiro: Jorge Zahar ed., 1985. - Le Séminaire. Livre IV. La relation d'objet. Paris: Seuil, 1994a. Le Séminaire, Livre IX, L'identification. Paris: Seuil, 1994b.

Ogilvie, Bertrand. Lacan: la formation du concept de sujet. (1932-1949). Paris: PUF, 1987.

Radzinski, Annie. "Lacan/Saussure: les contours théoriques d'une rencontre“. In Langages - Le sujet entre langue et parole(s) 77 (1985) : 117-124, Disponível em:http://www.persee.fr/docAsPDF/lgge_0458-726x_1985_ num_19_77_1509.pdf.

Rancière, Jacques. "O efeito de realidade e a política da ficção". Novos estudos 86 (2010). Disponível em: http://www.scielo.br/ scielo.php?script=sci arttext\&pid=S0101-33002010000100004.

Saussure, Ferdinand. Cours de linguistique générale. Paris: Gallimar, 2002.

Vicenzi, Eduardo. "Psicanálise e linguística estrutural: as relações entre as concepções de linguagem e de significação de Saussure e Lacan“. Ágora - Estudos em Teoria Psicanalítica 12 (1) (2009). Disponível em: http://www.scielo.br/scielo.php?script=sci_arttext\&pid=S151614982009000100002.

\section{Dicionários consultados:}

Association Lacanienne Internationale. "Le signifiant". In Dictionnaire. Sítio eletrônico. Disponível em: http://www.freud-lacan.com/index.php/fr/ dictionnaire/ 4577-le-signifiant. 
"Le sujet". In Dictionnaire. Sítio eletrônico. Disponível em: http:// www.freud-lacan.com/index.php/fr/dictionnaire/4577-le-sujet.

Vários. Grande Dicionário Houaiss da Língua Portuguesa. São Paulo: Objetiva, 2001.

Vários. Le Petit Robert de la langue française. Paris: Le Robert, 2000. 